\title{
The Effect of Specialised Instruction on The Level of Self- Assessment of Primary School Pupils in An Inclusive Environment: The Case of Kazakhstan
}

\author{
Kalykbayeva Almagul, Kazakh National Pedagogical University, almagulkalykbaeva@yandex.ru ORCID: \\ 0000-0001-5214-9526 \\ Satova Akmaral, Kazakh National Pedagogical University, satova57@mail.ru ORCID:0000-0002-2537-7184 \\ Baibekova Madina, International University SILKWAY, Kabdan.94@mail.ru ORCID:0000-0003-2053-5312
}

\begin{abstract}
The present study aims at investigating the effect of specialized instruction dealing with the development of primary school inclusive class pupils' levels of self-assessment. The participants of this study are the primary school inclusive classrooms pupils enrolled in state primary schools in Almaty. Overall 273 pupils participated in the study, 17 of which were pupils with special educational needs (SEN) whereas 256 were normal pupils. The study was conducted in the form of quasi-experimental research design and quantitative research method was used in analyzing the data with the help of SPSS program 23.0. Descriptive statistics (mean, std. deviation), as well as non-parametric test in terms of Mann Whitney $\mathrm{U}$ test and Wilcoxon test were used in the study. The results of the study indicated the positive effect of specialized instruction on both pupils' with SEN and normal students levels of self-assessment. There was found statistically significant difference in pupils' scores before and after the specialized instruction.
\end{abstract}

Keywords: inclusive education, primary school students, self-assessment.

Received: 15.11.2020 $\quad$ Accepted: 11.12.2020 $\quad$ Published: 16.01.2021

\section{INTRODUCTION}

Article 16 of the Republic of Kazakhstan Law On Education talks about the peculiarities of the content of general educational program: "General educational program of primary education is aimed at shaping the child's personality, developing his abilities, positive motivation and skills in learning activities: dynamic reading, writing, numeracy level, communications, autonomous self-realization, socialization, mastering the educational programs of the basic school" (Law of the RK). It is well known that the pedagogical process aims to develop the personality, both of a normative child and with special needs. The International Education for All Program considers inclusive education as an equal opportunity for all students to receive a quality education, to develop their potential, regardless of gender, socioeconomic status, ethnicity, geographic location, need for special education, age, and religion (UNESCO, 2003). Kazakhstan, having ratified, along with other international legal acts, the UN Convention On the Rights of Persons with Disabilities (in 2016) and On Combating Discrimination in Education (in 2017), demonstrates the political will to ensure the right to receive quality education for every citizen without any discrimination. Following the Conventions' main provisions, Kazakhstan undertakes to provide inclusive education at all levels (preschool, secondary, higher education institutions) (Standard educ., 2020). It is essential to understand that inclusive education is not taken separately; inclusiveness is a principle of the entire education system. It is not intended to make everyone the same (Peder Haug, 2010). Since the integration processes taking place in our country recently, contribute to the formation of a national model of inclusive education, taking into account the cultural and historical origin, artistic and pedagogical traditions, a critical rethinking of the best practices of European countries, experimental data of researchers, the level of moral development of society (Agavelyan, Aubakirova, Zhomartova, Burdina, 2020). Thus, the inclusion of students with special needs in general education is a natural stage in developing the education system in any civilized country globally, the social order of society, a certain level of economic, cultural, and legal development achieved. Special educational needs are the need for assistance and services in the educational process, carried out by psychological and pedagogical methods to ensure the success in teaching each student (Aidarbekova, 2015). The psychological basis for developing a person capable of finding his place in the world is adequate self-esteem. Of particular importance for the process of forming self-esteem is the age of the primary school period. At this age stage, psychic neoplasms appear, activities and social contacts expand, which create conditions for selfesteem in the future to become differentiated, adequate, generalized, and independent. 
Batyuta (2017), Bartosh (2016), Galeeva (2016), Sidorina (2017) and other scientists dealt with the main issues of identifying the patterns of self-esteem formation in children. The problem of selfesteem acquires particular relevance when it comes to children with extraordinary psychophysical development. These children have significantly reduced emotional background, emotional contact with adults is often broken. Because, for such children, self-esteem determines the success of their social integration. Therefore, the study of the features of its formation and correction is of global importance. As a teachers-defectologists note, due to impairments in personal and cognitive development, self-esteem in children with special educational needs is unique (Vygotsky, 1984). More than in ordinary children, it depends on the opinions of the people around them. Besides, the self-esteem of students with developmental disabilities in the educational process is more dependent on the success of educational activities than in ordinary children (Satova, Kalykbaeva, 2019).

That, in turn, involves using various appropriate methods for the individual peculiarities, abilities, and characteristics of the child's development.

Self-esteem from the scientists' point of view is the primary formation of the individual, which is a generalized (that is, stable, not situational) and a versatile result of self-knowledge: in activities, in thoughts, moral appearance, and interests, in ideals and motives of behavior, emotional and value attitudes towards oneself, which become a regulator of behavior in the future life of a person and is one of the main factors of personal development (Ambalova, 2016).

We consider the content of the concept of "self-esteem" as a psychological and pedagogical category, the structure of which includes cognitive, emotional, and behavioral components. The essence of the cognitive element of self-esteem lies in the mental operations of identifying oneself with other members of society, comparing one's characteristics with internal standards or the performance of others, and analyzing the degree of difference between these two values. The emotional component manifests itself in a person concerning himself. It is associated with a measure of satisfaction with his actions and the implementation of the intended goals. The behavioral component of self-esteem can be represented in a person's relationships with other people, in requirements for himself, in connection with his successes and failures. In the process of self-assessment, these components function in inseparable unity and, according to Chesnokova (2005), none of them can be presented in "pure form"

An important role for understanding the essence of self-assessment is the allocation of selfassessment functions. Being a complex system, self-assessment functions in different forms. The main characteristics of self-assessment include height, adequacy, reflexivity, stability, flexibility.

Zakharova(1989) in the framework of the structural-dynamic model of self-assessment, includes its main functions: motivational, regulatory, orientation, reflexive, signaling, evaluation, control, stimulating, blocking, and protective(Table 1).

Table 1. Functions of self-assessment and their content (essence)

\begin{tabular}{|l|l|l|}
\hline № & $\begin{array}{l}\text { Functions of self- } \\
\text { assessment }\end{array}$ & Content of the self-assessment function \\
\hline $\mathbf{1}$ & Motivational & $\begin{array}{l}\text { It is a prerequisite for the process of self- } \\
\text { assessment. }\end{array}$ \\
\hline $\mathbf{2}$ & Regulatory & $\begin{array}{l}\text { Provides self-realization, conscious } \\
\text { motivational activity of the individual. }\end{array}$ \\
\hline $\mathbf{3}$ & Orientation & $\begin{array}{l}\text { Provides orientation in the self-assessment } \\
\text { system. }\end{array}$ \\
\hline $\mathbf{4}$ & Reflexive & $\begin{array}{l}\text { It is manifested in the knowledge and } \\
\text { understanding of oneself, revealing how } \\
\text { others perceive a person, its features, } \\
\text { emotional reactions and representations. }\end{array}$ \\
\hline $\mathbf{5}$ & Signaling & $\begin{array}{l}\text { Determines the adequacy of a person's actions } \\
\text { and the degree of well-being of his life. }\end{array}$ \\
\hline $\mathbf{6}$ & Evaluative & $\begin{array}{l}\text { Contributes to the recognition of other } \\
\text { assessments, establishing a correspondence } \\
\text { between the personal opinion of oneself and } \\
\text { the opinion of others. }\end{array}$ \\
\hline $\mathbf{7}$ & Control & $\begin{array}{l}\text { Provides focus on upcoming actions, captures } \\
\text { erroneous actions. }\end{array}$ \\
\hline $\mathbf{8}$ & Stimulating & $\begin{array}{l}\text { Encourages to develop and improve qualities, } \\
\text { knowledge, skills. }\end{array}$ \\
\hline
\end{tabular}




\begin{tabular}{|l|l|l|}
\hline $\mathbf{9}$ & Blocking & $\begin{array}{l}\text { Regulates the degree to which the "I-concept" } \\
\text { maintains its stability under stressful } \\
\text { conditions. }\end{array}$ \\
\hline $\mathbf{1 0}$ & Protective & $\begin{array}{l}\text { Provides a choice of different strategies for } \\
\text { solving any tasks that are used to adapt to the } \\
\text { social environment. }\end{array}$ \\
\hline
\end{tabular}

Thus, the analysis of studies devoted to the problem of self-assessment allows us to conclude that self-assessment, as an integral quality of personality, is a psychological and pedagogical category and, as a system concept, includes cognitive, emotional and behavioral components that are in inseparable unity.

Based on the relevance of this problem we decided to develop and implement a specialized instruction on the basis of cognitive, emotional, and behavioural components of self-assessment.

The purpose of the article is to identify the effect of specialized instruction on the primary school learners' with and without developmental disabilities' level of self-assessment.

Based on the stated goal of the article, the answers to the following research questions were investigated:

- What are the levels of self-assessment of primary school students with and without special educational needs before the treatment?

What are the levels of self-assessment of primary school students with and without special educational needs after the treatment?

- $\quad$ Are there any statistically significant differences on the level of self-assessment of learners with special educational needs before and after the treatment?

Are there any statistically significant differences on the level of self-assessment of learners without special educational needs before and after the treatment?

\section{METHODS}

In the present study is a one group pretest-posttest design as a type of quasi-experimental design was used. The data obtained in the study was analyzed with the help of SPSS program 23.0. The study consisted of three phases. Initially, self-assessment evaluation form developed by the researcher was administered as a pre-test. As a second phase a specialized instruction based on the development of primary school students' levels of self-assessment was implemented during the class hours for six weeks. Finally, self-assessment evaluation form was administered as a post-test to evaluate the effect of specialized instruction on students' levels of self-assessment.

\section{Setting and Participants}

The participants of the research study consisted of 273 students with and without developmental disabilities who received primary education in two state primary schools in Almaty during the 2018-2019 academic year. 17 students out of 273 were the children with different developmental disabilities, whereas 256 were children without special educational needs. Demographic characteristics of participants are presented in tables 2 and 3.

Table 2. Demographic characteristics of participants according to special educational needs

\begin{tabular}{|l|l|l|}
\hline & N & Percentage \\
\hline Pupils' without disabilities & 256 & 93.8 \\
\hline Pupils' with disabilities & 17 & 6.2 \\
\hline Total & 273 & 100.0 \\
\hline
\end{tabular}

As it can be seen in Table 2, 16 students were with different disorders: 12 students were with delayed mental development; two were visually impaired; one was with mental retardation; one with language disorder; and one had autism.

Table 3. Demographic characteristics of participants according to grades

\begin{tabular}{|l|l|l|}
\hline Grade & $\mathrm{N}$ & Percentage \\
\hline $\mathbf{1}^{\text {st }}$ grade & 99 & 36.3 \\
\hline $\mathbf{2}^{\text {nd }}$ grade & 82 & 30.0 \\
\hline $3^{\text {rd }}$ grade & 92 & 33.7 \\
\hline Total & 273 & 100.0 \\
\hline
\end{tabular}


As shown in table 3, 36\% of participants were the first grade, $33.7 \%$ the second-grade and $30 \%$ were the third-grade pupils of primary school. Moreover, 6 of pupils with disabilities were from the third grade, 7 pupils from the second grade and 4 pupils from the first grade.

\section{Data Collection Instrument}

Self-assessment evaluation form developed by the researcher was used in the study. The evaluation form was consisted of such questions as: Do you love yourself? What are you most afraid of being at school? Have you got many friends? Are you having fun at school? Do you like answering these questions?, etc. The evaluation form was designed as a series of three-point Likert-type scale (3- sufficient enough; 2 partially sufficient; and 1-insufficient). Researcher evaluated each student participated in the research during the short interview.

To identify the children with special educational needs, before the initial stage of the research, appropriate methods of detection were applied such as "cut pictures", "conversation" and "Simple nonverbal analogies". It was also relied on the conclusions of the psychological, medical and pedagogical council (which children pass annually at the beginning of the school year).

\section{The experimental treatment}

In the present study an experimental treatment was implemented to investigate the effect of specialized instruction on development of self-assessment abilities of primary school pupils with and without special education needs.

During the treatment lasted for six weeks specialized instruction was implemented, which included special tasks to develop learners levels of self-assessment developed in accordance with the goals of the "SMART" principle developed by Kotova et al, (2015) on the basis of the Bloom taxonomy (1984). The tasks prepared allowed to determine, what knowledge and skills the children have mastered within the framework of a topic or section, and, ultimately, they facilitated the development of selfassessment skills. The positive aspect of this experiment is that the child becomes an independent expert (Pantiwati \& Husamah, 2017) of his/her own work. The developed tasks were examined by the expert professors. The tasks are aimed at determining the quality of learning, self-assessment and self-esteem in the inclusive education. At the initial stage of teaching, the teacher should first assess the levels of the student's achievements, which include: current developmental status of a child (CDS) and zone of proximal development (ZPD). From the pedagogical and didactic point of view, the following can be distinguished:

a) for the "recognition" level: the knowledge tasks within the framework of the studied educational material, containing the basic information.

b) for the "understanding, use" level: the tasks aimed at deepening of knowledge that the student already has. Such tasks require a more serious work approach and self-control from the students. The tasks are developed for staged performance, as a structural unit of the educational process and a topic corresponding to the training goals.

The pupils received the experimental treatment in addition to continuing the instruction in school. The developed special tasks provide significant opportunities for identifying:

1) the level of acquiring basic (elementary) knowledge;

2) the peculiarities of educational activities of a different order;

3) features of self-control and self-assessment at all stages of activity;

The first stage of this study included:

1) organization of the self-assessment process in accordance with the goals of the "SMART" principle.

2) the development of tasks and self-assessment techniques.

3) determining the inclusion of self-assessment during the class hours.

The program also included:

1) creating a psychologically comfortable educational environment

2) conducting preliminary work on self-assessment, a detailed explanation by the teacher of the phased implementation of the task (instruction)

3) creating a situation of success.

The model of development of self-assessment levels of primary school children in inclusive education as a factor of achievement of personal results was built on the basis of systematic and activitybased approaches, including target, theoretical and methodological, content-procedural and assessment blocks.

Each of the components included in these blocks is not completely independent, but interconnects with other blocks, has its own place in the overall structure, which is coordinated in a 
certain way by the purposefulness of the model. The components of each block and their interaction are determined by the action of general didactic and specific principles.

The target block of the model includes a goal and a system of tasks, the complex solution of which ensures its achievement. The goal - to form the self-assessment of the primary school children as a factor in achieving personal results of education - is specified by the following tasks: 1) to form the inner position of the student and the ability to self-knowledge; 2) to form the criticality and reflexivity of the individual; 3) to form a differentiated self-assessment of the primary school students.

The theoretical and methodological block includes methodological approaches (system and activity-based) and approaches of pedagogical interaction (student-centered, reflexive and facilitative), which are the basis for both the development of the model itself and the formation of self-assessment of senior school students as a factor in achieving personal educational results. Moreover, the solution to this problem is possible if the requirements and provisions of approaches that are closely interconnected, represent a system and contribute to the effective solution of the problem of self-assessment of primary school students as a factor in achieving personal educational outcomes.

The content-procedural block includes procedural, content, technological, and subject components. This block was implemented through a system of exercises, trainings, collective creative activities, etc., both in the regular and extra-curricular activities.

The assessment block reflects regular and extra-curricular activities and is carried out by us with maximum consistency through the development of assessment criteria, mutual assessment, selfassessment, reflection of our own achievements, etc. This block is implemented in terms of the evaluation, control, and reflexive functions of self-assessment, which are manifested in understanding oneself, identifying how others perceive a person, his features, and emotional reactions, contributing to the acceptance of other people's assessments, ensuring the focus of upcoming actions, and fixing erroneous actions.

\section{Data analysis}

According to the research questions, initially, to identify the levels of self-assessment of students with and without disabilities, descriptive statistics were performed (mean, std. deviation). Since there was significant difference in number of participants in two groups and one group consisted of 17 participants non-parametric tests were used during the analysis. Following, to determine whether there were any statistically significant differences between the students of two groups before and after the treatment in terms of their levels of self-assessment Mann Whitey U test was conducted. Moreover, to identify the effect of the special instruction on students' levels of self-assessment Wilcoxon test was performed by comparing scores before and after the treatment of both groups separately.

\section{FINDINGS}

Preliminary, descriptive statistics were performed in order to identify the initial levels of self-assessment of the students with and without disabilities.

Table 4. Descriptive statistics of learners before the treatment

\begin{tabular}{|l|l|l|l|}
\hline & $\mathrm{N}$ & Mean & Std.devation \\
\hline Pupils without disabilities & 256 & 2,08 &, 795 \\
\hline Pupils with disabilities & 17 & 1,76 &, 831 \\
\hline
\end{tabular}

From the results of descriptive statistics it is clear that there is a difference in mean scores of two groups. Pupils with SEN indicated M=1.76, whereas normal pupils mean scores indicated 2.08.

Following in order to look at the differences between two groups results in terms of their levels of self-assessment Mann Whitney U test was performed( Table 5).

Table 5. Difference between pupils' with and without disabilities before the treatment

\begin{tabular}{|l|l|l|l|l|}
\hline & $\mathrm{N}$ & Mean Rank & $\mathrm{U}$ & $\mathrm{p}$ \\
\cline { 1 - 3 } Pupils without disabilities & 256 & 138,81 & & \multirow{2}{*}{1711,5} \\
\cline { 1 - 3 } Pupils with disabilities & 17 & 109,68 & \multirow{2}{*}{17} \\
\hline
\end{tabular}

$* \mathrm{p}<.05$. 
The results of Mann Whitney test (see Table 5) revealed that there were no statistically signifficant difference between the students with and without disabilities with regard to their levels of self-assessment ( $\mathrm{U}=177.11 ; \mathrm{p}=.117)$ before the treatment.

Moreover, the descriptive statistics were conducted again to see the changes in learners mean scores after the treatment. Table 6 represents the results revealed from the descriptive statistics.

Table 6. Descriptive statistics of learners after the treatment

\begin{tabular}{|l|l|l|l|}
\hline & $\mathrm{N}$ & Mean & Std.devation \\
\hline Pupils without disabilities & 256 & 2,50 &, 719 \\
\hline Pupils with disabilities & 17 & 2,11 &, 871 \\
\hline
\end{tabular}

The learners with disabilities indicated $M=2.11$, whereas learners without disabilities showed higher mean score $\mathrm{M}=2.50$.

Similarly, Mann-Whithney U test was performed after the treatment. The results are presented in table 7.

Table 7. Between groups difference after the treatment

\begin{tabular}{|l|l|l|l|l|}
\hline & $\mathrm{N}$ & Mean Rank & $\mathrm{U}$ & $\mathrm{p}$ \\
\hline Pupils without disabilities & 256 & 139,43 & & \\
\cline { 1 - 3 } with disabilities & 17 & 100,35 & 1553,0 &, $022^{*}$ \\
\hline
\end{tabular}

$* \mathrm{p}<.05$.

As it is shown in table 6, there was found statistically signifficant difference between to groups level of self assessment after the treatment ( $\mathrm{U}=1553.0, \mathrm{p}=.022)$. The difference can be shown from the mean rank scores of two groups.

According to the third research the result of the students with disabilities before and after the treatmen were compared. To do it, Wilcoxon test was performed, the results of which you can seen in table 8.

Table 8. The difference in the level of self-assessment of learners with disabilities before and after the treatment

\begin{tabular}{|c|c|c|c|c|c|c|}
\hline & & $\mathrm{N}$ & Mean Rank & Sum of Ranks & $\mathrm{Z}$ & $\mathrm{p}$ \\
\hline \multirow{4}{*}{$\begin{array}{l}\text { Pupils } \\
\text { disabilities }\end{array}$} & wit $\quad$ Negative Ranks & $0^{\mathrm{a}}$ & 00 & .00 & \multirow{4}{*}{$-2,121^{b}$} & \multirow{4}{*}{$034^{*}$} \\
\hline & Positive Ranks & $5^{b}$ & 3,00 & 15,00 & & \\
\hline & Ties & $12^{c}$ & & & & \\
\hline & Total & 17 & & & & \\
\hline
\end{tabular}

$* \mathrm{p}<.05$.

Wilcoxon test results revealed that there was statistically significant difference between the scores of the group of students with disabilities before and after the treatment.

In order to compare pretest and posttest results of the group of learners without disabilities a paired samples t-test was conducted (Table 9).

Table 9. The difference in the level of self-assessment of learners without disabilities before and after the treatment

\begin{tabular}{|l|l|l|l|l|l|l|}
\hline & $\mathrm{N}$ & Mean & Std. Deviation & $\mathrm{t}$ & $\mathrm{df}$ & $\mathrm{p}$ \\
\hline Pupils without disabilities & 256 &,- 42578 &, 93848 & $-7,259$ & 255 &, $000^{*}$ \\
\hline
\end{tabular}

$* \mathrm{p}<.05$.

As a result (see table 7), it was found statistically significant difference between the pretest and posttest scores of the learners without disabilities $(\mathrm{t}=-7.259 ; \mathrm{p}=.000)$. If to compare the mean scores of the students without disabilities (tables 3 and 5) it is clear that the level of self-assessment significantly increased (Mean before=2.08; Mean after=2.50). 


\section{DISCUSSION AND CONCLUSIONS}

The results of this experimental work have shown that the special tasks developed in accordance with the goals of the SMART principle have effectively influenced the development of the self-assessment skills of both children with special needs and children with normal development. According to the results of statistical analysis it was established that there were no statistically significant differences between the children with normal development and the children with special needs regarding their self-assessment skills before the experiment. After six weeks of training based on the special tasks in accordance with the goals of the SMART principle, the obtained results showed positive dynamics in the development of selfassessment skills in both children with special needs and children with normal development. The statistically significant difference in the results of children with special needs before and after the experiment has been found. The same difference has been found in the results of children with normal development, which shows that the special training programme had a positive impact on the development of their self-assessment skills. It proves the efficiency of the developed programme for both the children with special needs and children with normal development.

The experimental works in the United States (Florida) (McLeskey; Waldron, Red, 2012) have been performed in order to make every student successful in inclusive education. The need for such research was one of the main motivating factors for teachers and administration. Creating conditions in all classes and providing high-quality instruction (Rosenshine, \& Stevens, (1986); Swanson (2008), in turn, has demonstrated high educational achievements of all primary school students (Ware, 2006). Taking into account the age peculiarities of the students, the educational resources and intensive support in acquisition of basic knowledge in reading and mathematics were applied, as a result of which the students have filled in the gaps in educational achievements. This study is focused only on the academic achievements of the students in inclusive education, where a limited number of schools were successful in applying this highly effective approach.

Some studies (Fuchs, Fuchs. D, Powell, Seethaler, Cirino, \& Fletcher, 2008) argue that the inclusive school will expand its activities, if it adheres to the following triad: professional training of teachers, multilevel approach and highly effective training strategies. The principles and strategies of inclusive practice correlate in the above mentioned studies. We cannot deny the fact that the assessment is essential both for children with special needs and normal development.

The approaches and strategies applied in the inclusive education shall work at the level of each stage of training (class), which corresponds to the educational level of each student sitting at the desk. Each educational institution shall meet the requirements and standard of education in provision of high-quality educational services. However, each school working in the inclusive format shall meet the needs of each student, taking into account both psychological and individual characteristics. In educational practice, the individual educational and didactic materials (Eliseeva ,Ersarina, 2019) became widespread, which are specially prepared by the teacher, taking into account the personal characteristics and capabilities of the students. But the school practice and conducted researches show the other situation: lack of time, appropriate competence of teachers and an insufficient number of students in each class.

In our study we do not exclude the psychological aspect, in which the self-esteem of the children with special needs in the educational process depends on the success of educational activities. The developed tasks allow: 1) the teacher to check the current level of acquisition of the initial basic knowledge. Since the task hierarchy begins from the low level of "recognition", "understanding», etc. The special tasks allow: 2) the children: to check their level, i.e at which level they are, while the student can adequately assess the level he/she has mastered by performing a relevant task. Thus, through the assessment of his/her work (that is, self-assessment) of the students with both special needs and normal development, the self-esteem is developed (the knowledge and assessment itself are confirmed). Assessing educational achievements in an inclusive classroom should be an educational process component. That would ensure the knowledge assimilation, subject skills mastery in academic subjects, and the disciplinary development of the psychological readiness elements for schooling, creating conditions for successful development educational activities (Bozkurt, 2020). Based on the foregoing, a clear picture of monitoring of each student is revealed, which does not require a special system.

Based on the foregoing, it is necessary to include the self-assessment tasks and techniques in the educational process based on the following principles:

1) regularity - aimed at the development of self-assessment skills

2) involvement - requires involvement of each student of inclusive education in the assessment of his/her educational achievements

3) integrated approach - inclusion of self-assessment techniques in each subject 
4) adequacy - involvement of the students in the assessment of their classmates (this will allow seeing the other mistakes, realizing themselves in the place of other students)

5) objective self-assessment - creation of emotionally positive attitude towards the children with special needs, and this entails both academic and personal success

6) integration of the self-assessment process in the educational process.

The main indicator of development of the students is the development of the self-assessment skills as individual abilities. The long-term goal of self-assessment is the achievement of the full responsibility of the student for the process and the result of the self-assessment activities. The development of selfassessment is understood to be the new formation of the personality of a student with special needs as an objective and dynamic development resulting in the adequate self-esteem of a student.

Based on the results of the experimental work of the study, the following can be noted:

1. The work performed at the confirmation stage has shown that the level of self-assessment skills in secondary schools is below average and requires improvement.

2. At the formation stage, the tasks prepared in accordance with the goals of the SMART principle for each class of the primary school allowed to develop their self-assessment skills. The children with special needs have insufficient results, therefore, the regular work aimed at their improvement is necessary. The main task of a school training course is the development of the students' conscious and strong skills. The development of possible skills can be proved by the ability of the students to assess their own work and convince of the correctness of the results obtained. The level of mastering the skills is achieved in the conditions of their purposeful development. That's why during the lessons, great attention should be paid to the various self-assessment techniques and tasks. In the course of formation of the self-assessment skills, the speed of reaction, ability to concentrate, need for self-control and culture of self-assessment are developed. Participation of the students in the self-assessment process is one of the conditions of the new assessment practice.

Gratitude

We express our deep gratitude for the organization and conduction of the study to the administration, teachers and students of the primary school of the secondary schools of Almaty.

\section{REFERENCES}

Agavelyan R.O., Aubakirova S.D., Zhomartova A.D., Burdina E.I. (2020). Teachers' Attitudes towards Inclusive Education in Kazakhstan. Integration of Education, 24(1),8-19.doi: https://doi.org/10.15507/1991-9468.098.024.202001.008-019

Ambalova S.A. (2016). Problems and mechanisms of manifestation of anxiety in primary school students. Baltic Humanitarian Journal, 3 (16), 86-89 (in Russ.).

An open file on inclusive education. UNESCO, 2003.

Aydarbekova A.A. (2015). Creation of a socially humane environment in organizations of general education. 64 p., Almaty (in Russ.).

Batyuta M.B., Sidorina E.V. (2017). Features of the influence of the style of family education on the level of self-esteem of primary schoolchildren. Modern scientific research and innovation (4), 797-800 (in Russ.).

Bozkurt, F. (2020). Teacher Candidates' Views On Self And Peer Assessment As A Tool For Student Development. Australian Journal of Teacher Education,45(1),47-60. http://dx.doi.org/10.14221/ajte.2020v45n1.4

Eliseeva I.G., Ersarina A.K (2019). Psychological and pedagogical support of children with special educational needs in general education schools: methodological recommendations. NNPC KP. 118 p. (in Russ.).

Fuchs, L., Fuchs, D., Powell, S., Seethaler, P., Cirino, P., \& Fletcher, J. (2008). Intensive intervention for students with mathematics disabilities: Seven principles of effective practice. Learning Disability Quarterly, 31, 79-92

Galeeva E.V., Bartosh N.N. (2016).Pedagogical conditions for the development of dialogical speech in senior preschool children. Baltic Humanitarian Journal. V 5, 2 (15), 127-131 (in Russ.).

Chesnokova, I. I. (2005). Self-Awareness of the individual. [Electron.resource] Mode of access: http://personpsy 2005.narod.ru

Haug, Peder (2010).Approaches to empirical research on inclusive education. Scandinavian Journal of Disability Research, 12( 3), 199-209

J. McLeskey, N. L. Waldron, L. Red.(2012). A Case Study of a Highly Effective, Inclusive Elementary

School.The Journal of Special Education,(5),86-98.https://doi: 10.1177/0022466912440455

Kotova N.V., Ilyasova D.S., Zhurba L.V., Fazylova G.Sh., Rakhymzhanova B.K. (2015). Formative 
assessment in teaching: SMART goals and success criteria. AOO «Nazarbayev Intellectual Schools» center of pedagogical excellence, 42 p. (in Russ.).

Pantiwati, Y., \& Husamah (2017). Self and Peer Assessments in Active Learning Model to Increase

Metacognitive Awareness and Cognitive Abilities. International Journal of Instruction, 10(4),185-202. https://doi.org/10.12973/iji.2017.10411

Psychological and pedagogical support of children with special educational needs in a secondary school: methodological recommendations. Almaty: NNPC KP, 2019.118 p. (in Russ.).

Rosenshine, B., \& Stevens, R. (1986). Teaching functions. In M. C. Wittrock (Ed.), Handbook of research on teaching (3rd ed., p. 376-391). New York, NY: Macmillan

Satova A.K., Kalykbaeva A. (2019). Organization of the process of self-assessment of children with

special educational needs as a psychological and pedagogical problem. Bulletin of KazNPU named after Abai, Psychology, 2 (59), 9-12 (in Russ.).

Standard educational programs for students with disabilities 0-4 grades primary education level

on the updated content. Order of the Ministry of Education and Science of the Republic of Kazakhstan dated February 5. Astana, 2020, No. 51 (in Russ.).

Swanson, E. (2008). Observing reading instruction for students with learning disabilities: A synthesis. Learning Disability Quarterly,(31),115-133.

Taxonomy of Educational Objectives (1984) Book 1: Cognitive Domain by Benjamin S. Bloom, 207p.

Tereshchenko E.S. (2017). Self-esteem in the personality structure of a younger student. Bachelor's degree. N 3-4, 31-34 (in Russ.)

The Republic of Kazakhstan Law On Education

Vygotsky, L. S. (1984). Sobranie sochinenij: V 6-ti tomakh. T. 4. Detskaya psihologiya [Collected works: In 6 volumes. Vol. 4. Child psychology]. Moscow: Pedagogika.

Ware, B. (2006). Warm demander pedagogy: Culturally responsive teaching that supports a culture of achievement for African American students. Urban Education, (41), 427-456.

Zakharova, A.V. (1989) Structural and dynamic model of self-assessment. Questions of psychology,(1),5-14. 